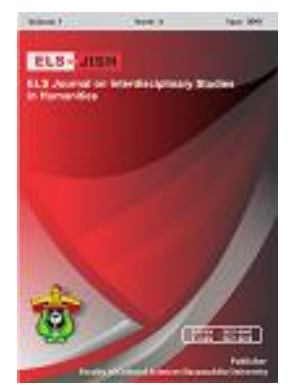

ELS-JISH

ELS Journal on Interdisciplinary Studies on Humanities

Volume 2 Issue 2, 2019

ISSN (print) : 2621-0843

ISSN (online) : 2621-0835

Homepage : http://journal.unhas.ac.id/index.php/jish

\title{
WhatsApp and Learn English: a Study of the Effectiveness of WhatsApp in Developing Reading and Writing Skills in English
}

\author{
Sabri Thabit Saleh Ahmed ${ }^{1}$ \\ 1 sabri-t2010@hotmail.com
}

\begin{abstract}
This study has examined the effectiveness of using WhatsApp, as one of mobile-assisted language learning applications, in enhancing learners' reading and writing skills in English. Twenty EFL undergraduate students of Aden University participated in a WhatsApp English medium group with the researcher where they and the researcher chat, share news articles and comment on news articles for two months. During this period, the researcher was observing their progress and then, they were given a questionnaire to report their experience about the effectiveness of WhatsApp in developing their reading and writing skills. Findings from students' pre-test and post-test, researcher's observations of students' progress and students' responses to the questionnaire revealed that WhatsApp was very effective in developing their reading and writing skills. It helped them a lot in developing their vocabulary, grammar, reading comprehension and writing skills. The study concluded that WhatsApp English medium groups provide space for practising natural language, especially in written communication, keep students learn and practice English outside the classroom and motivate them to learn from each other. As per the findings, the study has recommended EFL teachers to use WhatsApp in their teaching of English and to motivate their students to create and join WhatsApp English medium groups as that will help them in developing students' language proficiency through natural interaction and contextualized language use that can't be provided by the classroom.
\end{abstract}

Keywords: WhatsApp, mobile-assisted language learning, EFL learning, Aden University.

How to cite: Ahmed, S.T. S. (2019). WhatsApp and Learn English: a Study of the Effectiveness of WhatsApp in Developing Reading and Writing Skills in English. ELS Journal on Interdisciplinary Studies in Humanities, 2 (2), 148-156.

\section{Introduction}

One of the new fields of research in language learning and teaching is the use of mobile in language teaching and learning (MALL). There are many mobile applications that we can access today through our smartphones for learning English such as, dictionaries, MP3s, videos, PDFs, WhatsApp, facebook, twitter, youtube, web-based language learning,...etc. This new technology in language education is considered a great development in the $21^{\text {st }}$ century. In the past, language learning was limited to classroom and textbooks but today information and communication

${ }^{1}$ Faculty Member, Department of English, University of Aden, India 
technology has provided language learners with many applications and programs for developing his language through computers, internet, mobile smartphones ...etc. that one can use in and outside the classroom (Lee, 2000; Eslit, 2014; Zayed, 2016; Qasem, Ahmed and Pawar, 2019).

According to Oxford (1991), Savignon (1997) and Ahmed and Pawar (2018) communicative competence can be developed through realistic interaction using meaningful and contextualized language. However, time inside the classroom is not enough to practice the four languages skills and classroom in itself is more institutionalized and can't provide a pure contextualized language use and interaction. So there is a need for searching for other alternative that help the teacher to make students interact in a natural situation. The researcher believes that social media can help to achieve such a goal and should be investigated to examine their effectiveness in enhancing foreign language learning.

Based on these views presented above, the researcher believes that, with the help of the technology available at hand, creating WhatsApp groups of an English medium can be an easy and effective tool for developing students' EFL learning; and for this reason he requested twenty EFL students of Aden University to join whatsapp group of English medium to examine its effectiveness in developing their reading and writing skills.

\section{Literature Review}

Todays' students are known as 'digital natives' (Prensky, 2007) or internet generation. This means that they use internet and digital technology devices such as computers and smartphones in many aspects of their lives including their education and language education. This field of mobile-assisted learning has attracted many researchers during last decades due to the technological advancement and the widespread of mobile phones. It has been acknowledged that mobile learning (Mlearning) has a great value in various educational settings, e.g. collaborative learning (Hine, Rentoul, \& Specht, 2004), independent learning (Bull \& Reid, 2004), lifelong learning (Attewell \& Savill-Smith, 2004) and English as foreign language learning (Liu, Yu, \& Ran, 2008).

CALL and MALL are viewed as new development in language learning and are supported by many online and offline applications that are effective for language learning. Many studies have dealt with CALL's effectiveness in language learning and the problems related to CALL implementation in language learning. According to Warschauer and Healey (1998) CALL provides many benefits to language learning and teaching such as: "1- multimodal practice with feedback, 2- individualization in a large class, 3- pair and small-group work on projects, either collaboratively or competitively, 4- the fun factor, 5- variety in the resources available and learning styles used, 6- exploratory learning with large amounts of language data, and 7- reallife skill building in computer use". On the other hand, there are some challenges that teachers and students encounter with CALL; such as, the high price of computer, lack of internet, lack of training to use it...etc. These problems can be answered by MALL as mobile phones are cheaper as compared to computers, more spread and used around the world, easier to easier to take and use in spare time in different places as they are small in size and connected to the internet via sim-card. Miangah and Nezarat (2012) have confirmed that "although going through language activities 
on mobile phones may take longer time compared to computers, the learners feel a greater sense of freedom of time and place, so that they can take the advantage of spare time to learn a second language when and where they are". In the following paragraphs, this study will survey some previous research dealing with using whatsapp application in developing language learning.

Allagui (2014) has explored the effectiveness of WhatsApp instant text messaging on undergraduate students' writing skills. A group of 50 students were given a written assignment and were required to text messages one another through whatsapp messenger for the purpose of developing their writing skills. The participants then reported on their experiences through a survey after completion of the writing assignment. Though students' holistic scores remained low, they seemed to have benefited from the spell checker as they have received better scores in the area of spelling and vocabulary. The results also showed that the use of WhatsApp in the classroom increased students' motivation to write.

Abdul Fatah (2015) has conducted a study to determine the effectiveness of using a WhatsApp messenger to develop students' writing skills of Saudi private university students. 30 students participated in the study where the experimental group ( $n=15$ ) used WhatsApp to develop their writing skills and the control group $(n=15)$ was taught their writing skills through the prescribed book. Findings from pretest and post-test showed that WhatsApp technique yielded significant effects on students' writing skills, i.e. the experimental group outperformed the control group.

Jafari and Chalak (2016) have examined the role of whatsapp in teaching vocabulary to Iranian EFL junior school students. 30 male students and 30 female students participated in this study. The researchers used a pretest and post-test to assess the students' vocabulary level before and after the study. Then, the experimental group received vocabulary instructions, four days a week, for four weeks by using the WhatsApp while the control group was taught vocabularies of their textbook inside the classroom by traditional method used in all Iranian schools for teaching English to students. The results revealed that using WhatsApp in teaching vocabulary had a significant role in vocabulary learning. The results have also shown that there was not a substantial difference between male and female students regarding their vocabulary knowledge after using WhatsApp.

Ta'amneh (2017) has studied the effect of using WhatsApp messenger on learning English among university students. He has conducted his study on 40 students whom he divided into a control group (21) and an experimental group (19). His findings showed differences in the achievements of the two groups in favour of the experimental group. These differences indicate that integrating whatsApp application in teaching English language improved the abilities of the learners of the experimental group.

Hamad (2017) has conducted a study to examine the use of whasapp in enhancing Saudi tertiary learners' writing in English. The population of the study were 36 female students from 1st level who were studying Listening \& Speaking 1 course in the 1st semester 2013-2014. The data were collected through students' questionnaire and instructor observation. Findings showed that using WhatsApp enhances students' learning and enthusiasm, helps students to develop English skills, enriches their vocabulary, makes them learn from their mates' mistakes 
Annamalai (2019) explored the use of WhatsApp chat group as a platform for extending learning in a blended learning classroom with a small group of undergraduates in the Malaysian context. The aim of her study was to provide learners with the opportunity to reflect the strengths and challenges of using the WhatsApp as an extended learning platform. Findings revealed that the majority of the students expressed the preference for WhatsApp in their reflections in spite of the problems they face.

The above mentioned studies have examined the effectiveness of whatsapp in developing learning, language learning, vocabulary learning, writing and speaking. As there is only a limited number of studies that examined whatsapp, as one of mobile-assisted language learning application, the researcher feels that there is a need for more studies to deal with this topic and for this reason he decided to examine the effectiveness of whatsapp in developing two major language skills 'reading and writing' which are less investigated in previous research conducted on whatsapp and language learning. The researcher also believed that researchers should look for other channels that help students to interact and thinks that social media is a good space for achieving such a goal.

\section{2-1: Objectives of the study:}

This study aims at examining the effectiveness of whatsapp on developing EFL students' reading and writing skills.

\section{2-2: Hypothesis of the study}

This study has hypothesized that using whatsapp English medium groups for chatting and sharing news articles with requesting students to read and comment on are effective in developing students' reading and writing skills.

\subsection{Research Methodology}

This study presents a practical work that examined the effectiveness of WhatsApp on developing students' reading and writing skills in English as a foreign language.

\section{a- Participants:}

The participants of this study are twenty undergraduate students belong to English language department of Radfan College of education. They were requested to join a whatsapp group for developing their English, especially in reading and writing skills. All the participants are male gender as female students feel not comfortable to participate in whatsapp group and share the mobile numbers with their male classmates for social considerations.

\section{b- Data collection instruments:}

The data were collected through pre-test and post-test, researcher' daily observations of students' progress and a questionnaire given to the participants at the end of the study. The pre-test and post-test based on reading and writing tasks given to students when they joined the group and later on at the end of the study period in addition to assessing their chats in the group in the first week. Researcher's daily observations aimed at noticing students' progress in reading and writing. A questionnaire prepared by the researcher was also given to the students to examine 
their opinions regarding the effectiveness of the whatsapp in developing their reading and writing skills based on the experience they had during the study.

To validate the data collection tools, the researcher has sent the test and the questionnaire to five EFL Yemen professors. Their recommendations and comments were considered in the final draft of the test and the questionnaire.

\section{c- The study}

Twenty male EFL undergraduate students of Radfan college of Education were added to a WhatsApp group of English medium. The purpose of the study was to examine the effectiveness of the whatsapp in developing students' reading and writing skills. In the first week, the researcher chatted with the participants about different issues (issues related to their education, social and political issues) in order to assess their reading and writing skills. He gave tasks in reading and writing to assess their reading and writing skills. Then, from the second week onwards, he shared with them articles from newspapers, almost one article per day, and requested them to read and comment on its content or to paraphrase it in their own language. The rest of the time, the researcher and the members of the group exchanges different informal chats and discussion about several thing. Most of the issues discussed in the group are personal issues, issues related to their education, social and political issues as the country was in state of war and political unrest during the study. The researcher told the students to chat freely and to consider him as one of them and not to deal with him as a teacher as he no more teaches them at college due to his being study abroad. The researcher intended to send questions, debates and news articles from time to time about the war situation latest news, stories, students' education and activities they have...etc. to motivate discussions and make sure that the group works well towards its aim. During the course of the study, the researcher was observing students' progress in terms of grammatical accuracy, vocabulary development, length of writing and comprehension of the text given to them. At the end of the study, the researcher requested the students to write an article about the war in Yemen and their views of the future to assess their writing (the same task he gave at the beginning of the work). He also gave them one article to read and answer questions related to it in order to assess their reading comprehension (post-test). For the purpose of triangulation and to check students' opinions about the effectiveness of whatsapp in developing reading and writing skills, participants were requested to respond to a questionnaire with reference to their experience with the whatsapp during the last two months.

\section{Findings and discussion}

When comparing students' reading comprehension and writing skills in the first week and the last week of the study (pre-test and post test) as shown in table no 1 \& 2 , the researcher has found out a significant development in students' performance grammatically, lexically, length of their writing and in their reading comprehension as well. This development reflects that whatsapp chatting and the other activities shared in the group helped them in improving their reading comprehension and writing skills. Students' vocabulary store seems to be different as students by the end of the work can use political terms and other vocabulary in their writing and can write nicely too. This development in vocabulary and writing supports Jafari and Chalak' (2016) study of the effectiveness of whatsapp in developing students' vocabulary and Abdul Fatah' 
(2015) study in terms of whatsapp role in developing writing skills. In the first week of the study, only a few students were able to chat and write full sentences free of grammatical errors in English while the majority can write short phrases full of grammatical errors. Participants' answers to reading test also show students' weakness in dealing with political terms and newspaper language as only few students who performed well in the reading test while the performance of the majority was poor and very poor.

Table 1: Students' categorization based on their performance in the pre-test

\begin{tabular}{lllllll}
\hline Skills / Grade & Excellent & V. good & Good & Satisfactory & Poor & $\begin{array}{l}\text { Very } \\
\text { Poor }\end{array}$ \\
\hline Vocabulary & 1 & 3 & 4 & 1 & 6 & 5 \\
\hline Grammar & 2 & 2 & 4 & 4 & 4 & 4 \\
\hline $\begin{array}{l}\text { Reading } \\
\text { comprehension }\end{array}$ & 1 & 2 & 3 & 4 & 6 & 5 \\
\hline Writing & 0 & 2 & 3 & 4 & 7 & 4 \\
\hline
\end{tabular}

Table 2: Students' categorization based on their performance in the post-test

\begin{tabular}{lllllll}
\hline Skills / Grade & Excellent & V. good & Good & Satisfactory & Poor & $\begin{array}{l}\text { Very } \\
\text { Poor }\end{array}$ \\
\hline Vocabulary & 6 & 4 & 4 & 3 & 2 & 1 \\
\hline Grammar & 5 & 6 & 5 & 2 & 1 & 1 \\
\hline $\begin{array}{l}\text { Reading } \\
\text { comprehension }\end{array}$ & 5 & 5 & 6 & 2 & 1 & 1 \\
\hline Writing & 4 & 7 & 3 & 3 & 2 & 1 \\
\hline
\end{tabular}

During the course of the study, the researcher was observing the progress students achieve in their reading and writing skills as students learn from the group correct their errors and participate actively in daily activities. It has been noticed that those students who are poor were learning from their high level classmates and that was reflected from the vocabulary used by both students. The vocabulary used by high level students are to be found in low level students' writing after some days. This means that whatsapp group chatting helped poor student to learn from the good students as they have opportunities to look at their writings and to learn from it. It is something that is too difficult for classroom to provide to a high level.

In the last week of the study, the situation was completely different where most students became able to write comments and reports of many paragraphs with an acceptable level of accuracy. Students were also able to read, comprehend and interpret news articles. This was reflected in their post -test and their informal chats too. Such findings led the researcher to a conclusion that whatsapp English chats and the other tasks shared with students through the whatsup group were of great value in developing students' reading and writing skills. Whatsapp groups give students chances for communication in English, develop their grammar, vocabulary, reading comprehension and writing skills. It provides them with opportunities for learning from each other and keeps English ongoing outside their classroom.

So far as students' responses to the questionnaire are concerned, findings of the questionnaire, as shown in table no. 3, also support the researchers' observations and assessment. It has been revealed that through their experience 
with whatsapp learning, students expressed positive attitudes towards learning English through whatsapp and they consider whatsapp English medium groups of high significance in developing their reading and writing skills. They have emphasized that whatsapp chats and news articles shared via their whatsapp group during the two-month study helped them a lot to learn new vocabulary and grammar and to develop their reading and writing skills as a whole. They emphasized that whatsapp group chats motivate them to learn from each other and provide them with space to practice English as a means of communication. They agreed and strongly agreed that chats and tasks they had during this work were of high significance in developing their reading and writing skills.

Table 3. Descriptive Statistics of students' questionnaire regarding their experience with WhatsApp for developing their reading and writing skills

\begin{tabular}{|c|c|c|c|c|c|}
\hline Item & $\mathbf{N}$ & $\begin{array}{c}\text { Minimu } \\
\mathrm{m}\end{array}$ & $\begin{array}{c}\text { Maximu } \\
\mathrm{m}\end{array}$ & Mean & $\begin{array}{c}\text { Std. } \\
\text { Deviation }\end{array}$ \\
\hline $\begin{array}{l}\text { I like to use whatsapp for my language } \\
\text { learning. }\end{array}$ & 20 & 4.00 & 5.00 & 4.5000 & .51299 \\
\hline $\begin{array}{l}\text { Using whatsapp for language learning is } \\
\text { interesting and enjoyable. }\end{array}$ & 20 & 4.00 & 5.00 & 4.7500 & .44426 \\
\hline $\begin{array}{l}\text { Using whatsapp English medium groups is } \\
\text { effective for developing reading and writing } \\
\text { skills }\end{array}$ & 20 & 3.00 & 5.00 & 4.1000 & .85224 \\
\hline $\begin{array}{l}\text { Using whatsapp English medium group } \\
\text { helped me to develop my vocabulary }\end{array}$ & 20 & 3.00 & 5.00 & 4.3500 & .58714 \\
\hline $\begin{array}{l}\text { Using whatsapp English medium group } \\
\text { helped me to develop my grammar }\end{array}$ & 20 & 3.00 & 5.00 & 4.3000 & .73270 \\
\hline $\begin{array}{l}\text { Using whatsapp English medium group } \\
\text { helped me to develop my reading } \\
\text { comprehension }\end{array}$ & 20 & 4.00 & 5.00 & 4.3500 & .48936 \\
\hline $\begin{array}{l}\text { Using whatsapp English medium group } \\
\text { helped me to develop my writing. }\end{array}$ & 20 & 3.00 & 5.00 & 4.6000 & .59824 \\
\hline $\begin{array}{l}\text { Using whatsapp English medium group } \\
\text { helped me to learn from my friends. }\end{array}$ & 20 & 4.00 & 5.00 & 4.3500 & .48936 \\
\hline $\begin{array}{l}\text { Using whatsapp English medium group } \\
\text { provide me time to practise my English. }\end{array}$ & 20 & 3.00 & 5.00 & 4.4500 & .75915 \\
\hline $\begin{array}{l}\text { Using whatsapp English medium groups } \\
\text { motivates me to chat and learn. }\end{array}$ & 20 & 3.00 & 5.00 & 4.6500 & .58714 \\
\hline $\begin{array}{l}\text { Using whatsapp English medium groups } \\
\text { makes me free to ask questions and learn. }\end{array}$ & 20 & 3.00 & 5.00 & 4.3000 & .65695 \\
\hline $\begin{array}{l}\text { Using whatsapp English medium groups } \\
\text { provide me with more opportunities to } \\
\text { practice language than a classroom. }\end{array}$ & 20 & 2.00 & 5.00 & 3.9500 & 1.09904 \\
\hline Valid N (listwise) & 20 & & & & \\
\hline
\end{tabular}

When comparing their learning through whatsapp group and their classroom learning, participants emphasized that such chats, discussions and tasks given to them in whatsapp group during these two months were more effective in developing their reading and writing skills than classroom courses that they took for a four-month semester. They added that such whatsapp group provided them more time to practice reading, writing and communicating in English in comparison with classroom 
learning in which their teacher and few students participate in the practices while the majority of the students are passive listeners.

Based on the findings presented above, this study emphasizes the effectiveness of whatsapp on developing reading and writings skills and language generally. It provides students with real communication and language use that facilitate language acquisition to take place. Chatting and learning at the same time make language learning more motivating and enjoyable. It also helps students to learn from each other as each student presents his own unique style and his language that may help other students to learn something new.

\section{Conclusion and recommendations:}

This paper has examined the effectiveness of whatsapp, as one of the mobile techniques of language learning, on developing students' reading and writing skills. It has concluded that whatsapp English medium group is very effective in developing students' reading and writing skills as it helps students to develop their vocabulary, grammar, reading comprehension and writing skills. It provides students with good opportunities for practising English as a means of communication and helps students to learn from each other in an indirect way. For this reason, the study recommends EFL teachers to use whatsapp English medium groups in their teaching of English and to motivate their students to join such groups for chatting and learning.

\section{References}

Abdul Fattah, S. F. E. S.. (2015). The Effectiveness of Using WhatsApp Messenger as One of Mobile Learning Techniques to Develop Students' Writing Skills. Journal of Education and Practice, 6(32), 115-127. https://files.eric.ed.gov/fulltext/EJ1083503.pdf

Allagui, B. (2014). Writing through WhatsApp: an evaluation of students writing performance. International Journal of Mobile Learning and Organisation, 8(3-4), 216-231. DOI: 10.1504/IJMLO.2014.067022

Annamalai, N. (2019). Using Whatsapp to Extend Learning in A Blended Classroom Environment. Teaching English with Technology, 19(1), 3-20.

https://files.eric.ed.gov/fulltext/EJ1204549.pdf

Attewell, J., \& Savill-Smith, C. (2004). Mobile learning and social inclusion: Focusing on learners and learning. In J. Attewell \&, C. Savill-Smith (Eds.), Learning with mobile devices: Research and development (pp. 3-11). London, UK: Learning Skills and Development Agency.

http://citeseerx.ist.psu.edu/viewdoc/download?doi=10.1.1.97.4405\&rep=rep1\&ty pe=pdf

Bull, S., \& Reid, E. (2004). Individualised revision material for use on a handheld computer. In J. Attewell \&, C. Savill-Smith (Eds.), Learning with mobile devices: Research and development (pp. 35-42). London, UK: Learning Skills and Development Agency. http://citeseerx.ist.psu.edu/viewdoc/download?doi=10.1.1.97.4405\&rep=rep1\&ty pe=pdf

Eslit, E. (2014). Computer Assisted Language Teaching: Learning Without Dust. Retrieved from: 
https://www.academia.edu/11536522/COMPUTER ASSISTED LANGUAGE T EACHING LEARNING WITHOUT DUST

Hamad, M. M. (2017). Using WhatsApp to Enhance Students' Learning of English Language" Experience to Share". Higher Education Studies, 7(4), 74-87. https://files.eric.ed.gov/fulltext/EJ1161157.pdf

Hine, N., Rentoul, R., \& Specht, M. (2004). Collaboration and roles in remote field trips. In J. Attewell \& C. Savill-Smith (Eds.), Learning with mobile devices: Research and development (pp. 69-72). London, UK: Learning Skills and Development Agency. Retrieved form:

http://citeseerx.ist.psu.edu/viewdoc/download?doi=10.1.1.97.4405\&rep=rep1\&ty pe=pdf

Jafari, S., \& Chalak, A. (2016). The role of WhatsApp in teaching vocabulary to Iranian EFL learners at junior high school. English Language Teaching, 9(8), 85-92. DOI:10.5539/elt.v9n8p85

Lee, L. (2004). Learners' perspectives on networked collaborative interaction with native speakers of Spanish in the US. Language Learning \& Technology. Vol. 8, 83-100.

https://scholarspace.manoa.hawaii.edu/bitstream/10125/25231/1/08 01 lee.pdf

Liu, J., Yu, S., \& Ran, M. (2008). Research on the communicative mobile English learning model. In Fifth IEEE international conference on wireless, mobile, and ubiquitous technology in education (pp. 60-64). China: Wuhan.

DOI: $\underline{10.1109 / \text { WMUTE.2008.26 }}$

Prensky, M. (2007). Digital game-based learning. St. Paul, MN: Paragon House.

Oxford, R. L. (1991). Language learning strategies: What every teacher should know. Boston. Heinle

Qasem, Ahmed \& Pawar (2019). Students' Attitudes Towards Computer-Assisted Language Learning in Yemeni Context: A Case Study of Faculty of Languages - Aden. (Under publication process).

Savignon, S. J. (1997). Communicative competence: Theory and classroom practice: Texts and contexts in second language learning. McGraw-Hill Humanities Social.

Ta'amneh, M. A. A. A. (2017). The effect of using WhatsApp messenger in learning English language among university students. International Research in Education, 5(1), 143-151.

https://www.researchgate.net/publication/314982961 The Effect of Using Wh atsApp Messenger in Learning English Language among University Stude $\underline{\text { nts }}$

Zayed, N. M. (2016). Special Designed Activities for Learning English Language through the Application of WhatsApp!. English Language Teaching, 9(2), 199204. doi:10.5539/elt.v9n2p199 URL: http://dx.doi.org/10.5539/elt.v9n2p199 